a mistake in stating the relation of Momentum to Energy or wis vizra, and will endeavour to rectify it.

In quoting a dictum of the late Dr. Boole, Prof. Tait styles him the greatest logician the world has produced, or is likely to produce, for many a long day. In dissenting from this superlative, I do not refer to the men most widely known in recent years as logicians-Whately, Hamilton, Mill, Mansel ; I consider that the comparison of them with Boole fails through the dissimilarity of the matters compared; his Logic was but to a very small extent the Logic of any one of these writers. The only person who cultivated Logic in the manner of Boole was another noted mathematician, the veteran De Morgan. Now, without undertaking to say which of these two had the greater genius, I do not scruple to affirm that the labours of De Morgan, in their common department, if only through longer continuance in time, resulted in a much larger number of contributions to the science than can be credited to Boole. The two men were friendly co-operators, not rivals; and they will, I have no doubt, be mentioned together as often as reference is made to the Algebraic extensions of Formal Logic.

Aberdeen, Dec. 9

A. BAIN

\section{The Spectrum of the Aurora}

THE brilliant displays of the Amrora Borealis observed in England on the 24th of September and the 14th of October, I870, ${ }^{*}$ were also generally observed in this country. The fact may be worthy of record in your journal, as indicating the unusual extent of the phenomena. As the newspapers in different parts of the United States contained full descriptions of these displays, a detailed account need not here be given. I may remark, however, that they were generally regarded as the most brilliant displays we have had since 1859. Fine auroras were again witnessed on Monday morning, October $24^{\text {th, from } 5}$ to 6.30 A.M., and on the evening of the same day, from 6 to II P.M. At 9 P.M. (on the evening of the 24th) an auroral arch passed very nearly through the zenith from the eastern to the western horizon, or rather from a point a few degrees south of east, to another somewhat north of west. An extraordinary number of more feeble auroras have been noticed during the last two months.

Bloomington, Indiana, Nov. 9

\section{Can Aurora be Seen in Daylight?}

I VENTURE to believe not, in spite of circumstantial accounts to the contrary, and I ground my belief on the following considerations : $-\mathbf{r}$. No description of a daylight aurora that $I$ have ever seen will bear a critical examination. Take that published in the last number of NATURE. Here two arcs of faint white lines are said to have been seen in a direction "almost due east," and certainly the illustration given is not very unlike the appearance that auroral arcs sometimes present. But auroral arcs, so far as I know, never appear in the east, and the conclusion, therefore, is unavoidable that the object observed was nothing more than a remarkably symmetrical form of cirrus cloud. In another instance, lately published, although the thing described is called a daylight aurora, I fail to see in the description anything more than an account of the appearances presented when a high canopy of cloud clears off bodily from the sky with a sharp, straight edge, which by perspective becomes an arch. In the case referred to, the clouds clearing off from the direction of magnetic north, the arch corresponded in position with that of an aurora, and hence was set down as auroral. In a third account of a daylight aurora, it is expressly mentioned that the sky was hazy, and a solar halo visible, a condition of things which, while it would make the occurrence of aurora-like cirrus extremely probable, would be specially unfavourable to the visibility of a true aurora ; for certainly if so delicate and phosphorescent a light as that of an aurora is to be seen at all in the daytime, it can only be under circumstances the most favourable as regards clearness of the lower atmosphere.

2. A comparison of the auroral light with the light of other objects whose visibility can be more casily measured; tends strongly to confirm the view I have advanced. No one who remembers Donati's comet at its brightest will hesitate to allow that for intrinsic brilliancy that object surpassed the most vivid aurora. Yet Donati's comet at its brightest could not be detected

$$
\text { * Natere, Nos.49.50, and } 5 \mathrm{r} \text {. }
$$

with the naked eye until about half an hour after sunset, and then only the head could be seen.

3. The modifications of cirrus cloud are so infinitely diversified, and sometimes so very remarkable, as to offer a great temptation to the observer to invest them with the mysterious attributes of the aurora. Moreover, they do occasionally present a very striking resemblance to pencils of auroral light, differing, how ever, essentially in the character of fixity which they possess, as well as in the absence of any determinate relation to the magnetic pole or zenith.

On the grounds now stated $Y$ venture to refer daylight auroras in general to the large class of "errors of observation."

Clifton, Dec. I 3

GEORGE F. BURDER, M.D.

\section{The North London Naturalists' Club}

THE Secretary of the North London Naturalists' Club desires the Editor of NATURE to correct an incorrect statement which appeared in the last number of that journal. The North London Naturalists' Club is not broken up, it is not six years old, nor has it ever met on a Monday. Its last meeting was on Thursday, Nov. 24, at Myddelton Hall. Three subjects were then exhibited and explained, viz. "The Structure and Growth of the Yeast Plant," "The Structure of the Gastric Teeth in the Lobster," and "The Analomy of Amphioxus." The meeting was thinly attended, but that is no alarming phenomenon for societies of this kind. The previous meeting on Oct. 27 was a very full one, owing to a paper read by a deservedly well-known member of the club on the highly interesting subject of "Spontaneous Generation." It must be confesserl that the club is not so vigorous as when first started, but these facts show that it is by no means defunct.

$$
\text { J. SLADE, }
$$
Fon. Sec. N.L.N.C.

\section{Browning's Spectroscope}

IN the last number of NATURE there is a description by Prof. Young of a spectroscope, in which the prisms are made to alter their positions relatively to each other by bending backwards and forwards the metal work to which they are attached. I should of course not wish to offer any opinion on the efficiency or olherwise of this arrangement.

My reason for writing is that in the course of the article Prof. Young goes out of his way to remark that, in attaching bars at right angles to the bases of the prisms in my Automatic Spectroscope, I have adopted a plan of Mr. Rutherford's. Will you kindly permit me to state that I began my Automatic Spectroscope in the year $\mathbf{1} 862$, and that, so far as publication consists in exhibiting anything to a large number of persons, I had pub. lished it in the year 1863. I have reason to believe that M. Duboscq also attached bars in a similar manner to the bases of prisms with the intention of obtaining a minimum deviation adjustment, about the same time as myself, or scon afterwards. I do not know at what time Mr. Rutherford may have contrived his plan, but, as I have never read any description of his instrument, I must disavow having adopted any plan of his. At the same time I must remark that it is a small step towards obtaining the complicated movement required to produce an automatic minimum deviation adjustment, and it seems to me that it is a step every person would be likely to take who wished to obtain the adjustment by a mechanical motion.

III, Minories, Dec. 12

\section{JOHN BROWNING}

\section{Evolution of Light}

YOUR correspondent, who describes in the number of NATURE of the 17 th ult. a faint light observed by him on tearing strips from a woven fabric in the dark, may be interested to know that a similar phenomenon is noticed by $\mathrm{Mr}$. Grove in his "Correla. tion of Physical Forces," as occurring with indiarubber waterproof cloth (4th ed. p. 48).

Mr. Grove ranks it under phenomena of heat and light, rather than of electricity. C. J. T.

\section{Fungi}

IT is very unfair that the mushroom amily should lie under a ban, because Locusta, at the instigation of Agrippina, employed 